\title{
Importance of Vestibulo-ocular Reflex Gain and Refixation Saccade Analysis in Individuals with Auditory Neuropathy Spectrum Disorder
}

\author{
Sujeet Kumar Sinha ${ }^{1}$ Anuj Kumar Neupane ${ }^{1} \quad$ Krithika Gururaj $^{1}$ \\ ${ }^{1}$ Department of Audiology, All India Institute of Speech and Hearing, \\ Mysore, Karnataka, India \\ Address for correspondence Sujeet Kumar Sinha, PhD, Department \\ of Audiology, All India Institute of Speech and Hearing, Mysore, \\ Karnataka, India (e-mail: sujitks5@gmail.com). \\ Int Arch Otorhinolaryngol 2020;24:e140-e148.
}

\begin{abstract}
Introduction Auditory neuropathy spectrum disorder (ANSD) features the presence of otoacoustic emissions, poor speech identification score and absent auditory brainstem response.

Objective The present study was designed to evaluate the functioning of all six semicircular canals in individuals with ANSD and to compare it with those of normalhearing individuals.

Methods A total of 50 individuals participated in the present study, in which Group I comprised 25 normal-hearing individuals, and Group II comprised 25 individuals with ANSD. All of the participants underwent case history, pure tone audiometry, immittance, otoacoustic emissions, auditory evoked response and video head impulse test (vHIT).

Results The independent sample t-test revealed significantly lower vestibulo-ocular reflex gain values in individuals with ANSD. A presence of $100 \%$ corrective refixation saccades was observed in the same group. The Pearson correlation test revealed no significant correlation between vestibulo-ocular reflex (VOR) gain with duration of

\section{Keywords}

- auditory neuropathy

- semicircular canals

- vestibulo-ocular reflexes

- saccades

- pure tone threshold hearing loss and pure tone thresholds for any of the three orthogonal planes. The chisquared test revealed no association between the VOR gain values and the presence or absence of saccades in any of the semicircular canals $(p>0.05)$.

Conclusion Huge percentages of individuals with ANSD have been found to have associated vestibular dysfunction as well. Therefore, the vHIT can be used as one of the important tests of the vestibular test battery to evaluate all six semicircular canals in individuals with ANSD.
\end{abstract}

\section{Introduction}

Auditory neuropathy spectrum disorder (ANSD) is characterized by the presence of otoacoustic emissions, the absence of auditory brainstem response, and of poorer speech identification score that does not correlate with the pure tone threshold. ${ }^{1-4}$ The epidemiological data on ANSD varies across the studies and age groups. In 1979, Davis et al ${ }^{5}$ reported that 1 in every 200 children with hearing impairment have ANSD. Simi-

received

March 22, 2018

accepted

June 23, 2019

10.1055/s-0039-1697004. ISSN $1809-9777$. larly, in 1999, Berlin ${ }^{6}$ reported $4 \%$ of children with permanent hearing loss with ANSD. In the Indian scenario, it was reported that 1 in every 183 individuals with sensorineural hearing loss has ANSD, ${ }^{7}$ whereas the prevalence of ANSD was reported to be $2.27 \%$ in school-going hearing impaired children. ${ }^{8}$

The prevalence of vestibular impairment varies across studies. In a retrospective study on 50 individuals with ANSD, $53 \%$ of them were found to have vestibular dysfunction with hypoactive caloric response. ${ }^{9}$ Prabhu et $\mathrm{al}^{10}$ reported that one in five

Copyright $\odot 2020$ by Thieme Revinter

Publicações Ltda, Rio de Janeiro, Brazil

License terms

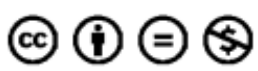


individuals with ANSD reported at least one of the vestibular symptoms. A few other studies have also reported affected sacculocollic $^{11-13}$ and utriculo-ocular pathways ${ }^{14}$ in these individuals. Also, abnormal response has been reported in the Mann, Romberg and Fukuda stepping tests for eyes closed condition suggesting a possible involvement of peripheral vestibular organs in individuals with ANSD. ${ }^{13}$

However, earlier studies have also reported variability in vestibular test results in individuals with ANSD. Sinha et al $(2013 b)^{13}$ reported abnormality of cervical vestibular evoked myogenic potentials (cVEMPs) in $82.26 \%$ of the ears with ANSD, Ismail et $\mathrm{al}^{15}$ reported absence of cVEMPs in $50 \%$ of the ears with ANSD, Kumar et al ${ }^{12}$ reported abnormal cVEMPs in $65 \%$ of the ears with ANSD, and Sinha et al $(2013 b)^{13}$ reported absence of ocular vestibular evoked myogenic potentials (oVEMPs) in $90 \%$ of the ears with ANSD. There was a large variability not only in the cVEMPs and oVEMPs, but also in caloric test findings. For example, Starr et $\mathrm{al}^{3}$ reported absent responses to caloric tests in $20 \%$ of the participants with ANSD, AbdelNasser et al ${ }^{16}$ reported reduced caloric responses in $30 \%$ of the subjects with ANSD, whereas Sinha et $\mathrm{al}^{17}$ reported reduced caloric responses in $86 \%$ of the participants with ANSD.

The caloric test is considered as a gold standard test for the evaluation of the 2 lateral semicircular canals in a very low and brief frequency range $(0.002-0.004 \mathrm{~Hz})$. However, the frequency range assessed by the caloric test is way below the frequency range to which a normal hearing individual is exposed in everyday life. ${ }^{18}$ Also, the caloric test does not assess the anterior and the posterior canal. Even after combining the cVEMP, oVEMP and caloric test results, we obtain information about the saccule, the utricle, and only the horizontal semicircular canals. Hence, there is a need to assess the anterior and the posterior canals in individuals with ANSD.

Halmagyi et al ${ }^{19}$ have come up with an advanced noninvasive tool based on the principle of the head impulse test (HIT), known as the video head impulse test (vHIT). The vHIT is a software-based test that consists of goggles with gyroscope to quantify the vestibulo-ocular reflex (VOR) gain function and refixation saccades. ${ }^{20}$ The vHIT has good test retest reliability ${ }^{21}$ and good sensitivity in identifying semicircular canal lesions in various clinical populations, such as Meniere disease, ${ }^{22}$ benign paroxysmal positional vertigo, ${ }^{23}$ vestibular neuritis, ${ }^{24}$ adults with congenital sensorineural hearing loss, ${ }^{25}$ and in vestibular migraine. ${ }^{26}$ The inclusion of the vHIT in the vestibular test battery for the diagnosis of vestibular lesions in individuals with ANSD will provide information about all the six semicircular canals.

Therefore, the present study aimed at evaluating the functioning of all six semicircular canals in individuals with ANSD and to compare it with those of normal hearing individuals. Vestibulo-ocular reflex gain function and refixation saccades (if any) in both groups were analyzed. The present study also aimed at finding out a correlation between vHIT test findings with duration of disorder and pure tone thresholds and finding out an association between the presence or absence of saccades with VOR gain values in individuals with ANSD (if any).

\section{Methods}

Two groups of individuals were included in the present study. Group I consisted of 25 participants ( 18 males and 7 females) in the age range of 16 to 40 years $(\bar{x}=22.16 ; \sigma=1.8)$ with bilateral hearing sensitivity within normal limits as examined with pure tone audiometry. Also, these individuals reported to have no history or presence of any otological, neurological or vestibular disorders. None of the individuals had been treated with any vestibulotoxic medications. Group II consisted of 25 participants ( 18 males and 7 females) in the age range of 16 to 40 years $(\bar{x}=29.20 ; \sigma=7.8)$ and diagnosed with bilateral ANSD. The diagnosis of ANSD was made based on poor word recognition scores, preserved otoacoustic emission/cochlear microphonics resembling normal OHCs (outer hair cells) functioning, abnormal auditory brainstem evoked potentials and absent acoustic reflexes. These individuals had no history or presence of any otological disorders. A neurological opinion was taken to further confirm the diagnosis of ANSD. A total of 5 out of 25 participants with ANSD presented with vestibular signs and symptoms. Demographic details, duration of the disorder, and audiological information of each of the individuals with ANSD are shown in - Table 1.

All of the testing procedures performed in the present study were noninvasive and were approved by the review

Table 1 Details of Degree, Duration and Configuration of Hearing Loss in Individuals with Auditory Neuropathy Spectrum Disorder

\begin{tabular}{|c|c|c|c|c|c|}
\hline Participants & $\begin{array}{l}\text { Age(years old)/ } \\
\text { gender }\end{array}$ & Ear & $\begin{array}{l}\text { Severity of hear- } \\
\text { ing loss }\end{array}$ & $\begin{array}{l}\text { Pure tone } \\
\text { configuration }\end{array}$ & $\begin{array}{l}\text { Duration of the } \\
\text { disorder (years) }\end{array}$ \\
\hline \multirow[t]{2}{*}{ P1 } & \multirow[t]{2}{*}{$40 / F$} & Right & Moderate & Reverse slope & \multirow[t]{2}{*}{1} \\
\hline & & Left & Moderately severe & Reverse slope & \\
\hline \multirow[t]{2}{*}{ P2 } & \multirow[t]{2}{*}{$35 / M$} & Right & Moderately severe & Reverse slope & \multirow[t]{2}{*}{1} \\
\hline & & Left & Moderate & Reverse slope & \\
\hline \multirow[t]{2}{*}{ P3 } & \multirow[t]{2}{*}{$38 / F$} & Right & Moderately severe & Flat & \multirow[t]{2}{*}{5} \\
\hline & & Left & Moderate & Flat & \\
\hline \multirow[t]{2}{*}{ P4 } & \multirow[t]{2}{*}{$19 / M$} & Right & Minimal & Flat & \multirow[t]{2}{*}{8} \\
\hline & & Left & Minimal & Flat & \\
\hline
\end{tabular}


e142 Importance of Vestibulo-ocular Reflex Gain and Refixation Saccade Analysis in Individuals Sinha et al.

Table 1 (Continued)

\begin{tabular}{|c|c|c|c|c|c|}
\hline Participants & $\begin{array}{l}\text { Age(years old)/ } \\
\text { gender }\end{array}$ & Ear & $\begin{array}{l}\text { Severity of hear- } \\
\text { ing loss }\end{array}$ & $\begin{array}{l}\text { Pure tone } \\
\text { configuration }\end{array}$ & $\begin{array}{l}\text { Duration of the } \\
\text { disorder (years) }\end{array}$ \\
\hline \multirow[t]{2}{*}{ P5 } & \multirow[t]{2}{*}{$40 / \mathrm{M}$} & Right & Minimal & Reverse slope & \multirow[t]{2}{*}{0.5} \\
\hline & & Left & Minimal & Reverse slope & \\
\hline \multirow[t]{2}{*}{ P6 } & \multirow[t]{2}{*}{$22 / \mathrm{M}$} & Right & Moderate & Flat & \multirow[t]{2}{*}{8} \\
\hline & & Left & Moderately severe & Flat & \\
\hline \multirow[t]{2}{*}{ P7 } & \multirow[t]{2}{*}{$26 / F$} & Right & Minimal & Reverse slope & \multirow[t]{2}{*}{1} \\
\hline & & Left & Minimal & Reverse slope & \\
\hline \multirow[t]{2}{*}{ P8 } & \multirow[t]{2}{*}{$32 / \mathrm{M}$} & Right & Moderate & Flat & \multirow[t]{2}{*}{2} \\
\hline & & Left & Moderate & Flat & \\
\hline \multirow[t]{2}{*}{ P9 } & \multirow[t]{2}{*}{$16 / F$} & Right & Moderate & Reverse slope & \multirow[t]{2}{*}{1} \\
\hline & & Left & Moderately severe & Reverse slope & \\
\hline \multirow[t]{2}{*}{ P10 } & \multirow[t]{2}{*}{$19 / F$} & Right & Moderate & Reverse slope & \multirow[t]{2}{*}{1} \\
\hline & & Left & Moderate & Reverse slope & \\
\hline \multirow[t]{2}{*}{ P11 } & \multirow[t]{2}{*}{$28 / \mathrm{F}$} & Right & Moderate & Flat & \multirow[t]{2}{*}{5} \\
\hline & & Left & Moderate & Flat & \\
\hline \multirow[t]{2}{*}{ P12 } & \multirow[t]{2}{*}{$26 / M$} & Right & Moderate & Flat & \multirow[t]{2}{*}{5} \\
\hline & & Left & Moderately severe & Sloping & \\
\hline \multirow[t]{2}{*}{ P13 } & $28 / F$ & Right & Moderately severe & Flat & 8 \\
\hline & & Left & Moderate & Sloping & \\
\hline P14 & $20 / M$ & Right & Moderate & Sloping & 16 \\
\hline & & Left & Moderate & Sloping & \\
\hline P15 & $37 / F$ & Right & Moderate & Flat & 5 \\
\hline & & Left & Moderate & Reverse slope & \\
\hline P16 & $17 / \mathrm{M}$ & Right & Moderate & Flat & 8 \\
\hline & & Left & Moderately severe & Flat & \\
\hline P17 & $38 / \mathrm{M}$ & Right & Moderate & Flat & 16 \\
\hline & & Left & Moderate & Flat & \\
\hline P18 & $33 / F$ & Right & Moderate & Flat & 5 \\
\hline & & Left & Moderate & Flat & \\
\hline P19 & $28 / \mathrm{M}$ & Right & Moderate & Flat & 5 \\
\hline & & Left & Moderately severe & Flat & \\
\hline P20 & $33 / F$ & Right & Moderate & Reverse slope & 2 \\
\hline & & Left & Moderate & Reverse slope & \\
\hline $\mathrm{P} 21$ & $26 / M$ & Right & Moderate & Flat & 5 \\
\hline & & Left & Moderate & Flat & \\
\hline P22 & $32 / F$ & Right & Moderate & Sloping & 2 \\
\hline & & Left & Moderate & Flat & \\
\hline P23 & $21 / \mathrm{M}$ & Right & Minimal & Flat & 1 \\
\hline & & Left & Minimal & Flat & \\
\hline P24 & $40 / F$ & Right & Moderately severe & Flat & 16 \\
\hline & & Left & Moderate & Flat & \\
\hline P25 & $60 / \mathrm{M}$ & Right & Moderate & Flat & 5 \\
\hline & & Left & Moderately severe & Flat & \\
\hline
\end{tabular}


board of the All India Institute of Speech and Hearing. Also, all of the procedures were explained to each individual taking part in the study, followed by written consent on the same.

A calibrated Inventis Piano Plus audiometer (Inventis, Padova, Italy) with a TDH-39 headphone (Telephonics Corporation, Farmingdale, NY, USA) encased in MX-41/AR supra-aural cushion (Telephonics Corporation, Farmingdale, NY, USA), and a Radioear B-71 bone vibrator (Kimmetrics, Smithsburg, MD, USA) were used for pure tone audiometry and speech audiometry. A calibrated Grason-Stadler Tympstar (version 2.0) (Grason-Stadler Inc, Eden Prairie, MN, USA) middle ear analyzer was used to analyze the functioning of the middle ear. Otoacoustic emissions were measured via a calibrated ILOV6 (version 2.0) (Grason-Stadler Inc, Eden Prairie, MN, USA). A calibrated Intelligent Hearing System (IHS) with Smart EP (3.94 USBez) system was used to measure click evoked auditory brainstem response. Video head impulse tests with ICS impulse lightweight video goggles (GN Otometrics, Taastrup, Denmark) and a camera with a speed of $250 \mathrm{~Hz}$ was utilized to record the motion of the right eye and to check for refixation saccades (if any).

All of the tests were performed according to the criteria of the American National Standard Institute (ANSI) S3.1 (1991) within noise permissible limit in an acoustically treated room. A detailed case history was taken regarding the nature and onset of the hearing loss and the presence of any vestibular symptoms. Also, detailed information on medical history and any other associated problems were obtained.

With the modified Hughson and Westlake procedure, ${ }^{27}$ air conduction and bone conduction thresholds were measured at octave frequencies from $250 \mathrm{~Hz}$ to $8,000 \mathrm{~Hz}$ and at $250 \mathrm{~Hz}$ to $4,000 \mathrm{~Hz}$, respectively, to evaluate hearing sensitivity of all of the individuals who participated in the present study. The tympanometry was performed at $226 \mathrm{~Hz}$ probe tone, and the acoustic reflex threshold was obtained at $500 \mathrm{~Hz}, 1,000 \mathrm{~Hz}, 2,000 \mathrm{~Hz}$ and $4,000 \mathrm{~Hz}$, both ipsilaterally and contralaterally. Transient evoked otoacoustic emissions (TEOAEs) were measured at $80 \mathrm{~dB}$ peak SPL with 260 pairs of click stimuli in probe fit condition. Otoacoustic emissions (OAEs) were considered present if the signal to noise ratio (SNR) was $>6 \mathrm{~dB}$ for 3 consecutive frequencies. The conventional electrode placement technique was used to measure auditory evoked brainstem responses using clicks of $100 \mu \mathrm{s}$ at a repetition rate of $30.1 /$ second, with a filter setting of 100 to $3,000 \mathrm{~Hz}$ in both condensation and rarefaction polarities.

The administration of the vHIT was performed in a well-lit room using the dedicated Otosuite vestibular software (GN Otometrics, Taastrup, Denmark). Lightweight goggles with frenzel glasses were fixed aptly to avoid slippage. The calibration of the instrument was performed for all of the individuals prior to the administration of the vHIT test. After the calibration of the equipment, head thrust was given for the lateral plane, the right anterior left posterior plane (RALP), and for the left anterior right posterior plane (LARP) for all of the participants. The head thrust was applied randomly at an angle ranging between $10^{\circ}$ and $15^{\circ}$ in all 3 orthogonal planes (pitch, roll and yaw planes).

The VOR gain for all of the six semicircular canals and the refixation saccades (if any) at the time of head thrust, that is, covert saccade, after the head thrust, and overt saccade were analyzed for all the participants.

\section{Results}

Descriptive statistics was performed to calculate the mean and standard deviation (SD) of the VOR gain between the two groups for all three planes of the semicircular canals. The vHIT responses recorded from one individual of each groups are given in -Figs. 1 and $\mathbf{2}$.

The VOR gain of all six semicircular canals was analyzed for both groups. The VOR gain was considered to be abnormal if the value of the VOR gain was $<0.8 .{ }^{28}$ According to the aforementioned criteria, the VOR gain was found to be $>0.8$ for all the normal hearing individuals for all the six semicircular canals, whereas most of the individuals with ANSD had reduced VOR gain $(<0.8)$ in $\geq 1$ semicircular canal. Only one of the participants with ANSD had normal VOR gain in all six semi-circular canals. The VOR gain data for each individual is shown in -Fig. 3.

The mean and SD of the VOR gain are shown in - Table 2.

From - Table 2, it can be observed that the VOR gain is reduced in individuals with ANSD compared with normalhearing individuals for all the six semi-circular canals.

The Shapiro-Wilk test revealed normal distribution ( $p>0.05)$ of the VOR gain data. The independent sample ttest revealed a significant difference in VOR gain values between the 2 groups for the right lateral (RL) ( $t$ $[48]=5.57 ; p=0.00)$, left lateral (LL) (t [48]=3.69; $p=0.00)$, right posterior (RP) (t $[48]=5.52 p=0.00)$, left anterior (LA) (t $[48]=5.17 ; p=0.00)$, right anterior $(\mathrm{RA})(\mathrm{t}$ $[48]=4.99 ; p=0.00)$, and left posterior LP ( $[48]=5.80$; $p=0.00$ ) canals.

Also, the refixation saccades were calculated across both groups, where they were found to be present in individuals with ANSD and absent in normal-hearing individuals. The overall frequency of refixation saccades in different planes in individuals with ANSD is shown in - Table 3.

- Table 3 shows the presence of saccades in individuals with ANSD. It can be seen that covert saccade alone was present in all of the six semi-circular canals in individuals with ANSD. Both the covert and overt saccades were present in all of the canals, except in the RA. Furthermore, the presence of only overt saccade was observed in all of the six canals, except in the LA and in the right anterior RA canals. The saccades were found to be higher in number for lateral canals. However, no saccades were observed in any of the normal-hearing individuals.

The Pearson correlation test was administered in individuals with ANSD to understand the correlation between the duration of the disorder with VOR gain. The Pearson correlation test revealed no significant correlation between the VOR gain values and the duration of the disorders. The correlation 
e144 Importance of Vestibulo-ocular Reflex Gain and Refixation Saccade Analysis in Individuals Sinha et al.
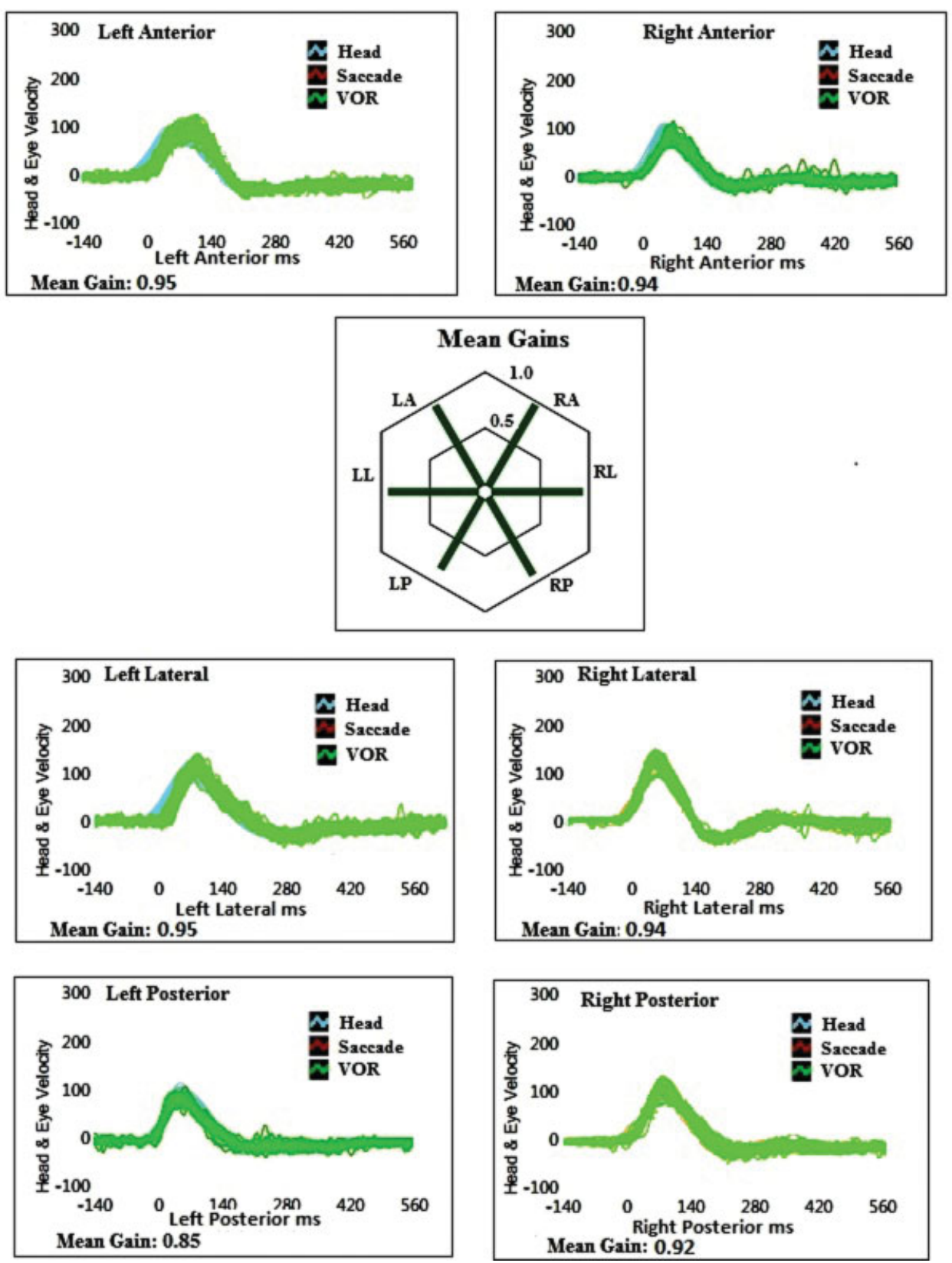

Fig. 1 Video head impulse test results obtained from one of the participants with normal hearing.

values between VOR gain and the duration of the disorder are shown in - Table 4.

The Pearson correlation test revealed no correlation between pure tone thresholds and the VOR gain values for the right canals and the left canals (except for the LP canal). Please note that the correlation was obtained between the right canals VOR gain values with right ear pure tone thresholds and the left canals with left ear pure tone thresholds. The correlation values for the VOR gain with pure tone thresholds are shown in - Table 5 .

An attempt was made to find an association between the VOR gain values and the presence or absence of saccades in individuals with ANSD. We have tried to find an association between the VOR gain of a particular canal with the presence or absence of saccades in that particular canal. For example, we have tried to find an association between the VOR gain of the lateral canal with the presence or absence of saccades in the lateral canal only. The chi-squared test revealed no association between the VOR gain values and the presence or absence of saccades in any of the semicircular canals $(p>0.05)$. The summary of the chi-squared test is shown in - Table 6

\section{Discussion}

The results of the present study revealed significantly lower VOR gain values in individuals with ANSD than in normal hearing individuals. Similar studies have reported reduced VOR gain in individuals with various peripheral vestibular disorders. ${ }^{29,30}$ Blödow et al $^{31}$ reported unusually decreased VOR gain values in 117 patients with bilateral vestibulopathy. Blödow et $\mathrm{al}^{23}$ reported reduced VOR gain values in $37 \%$ 

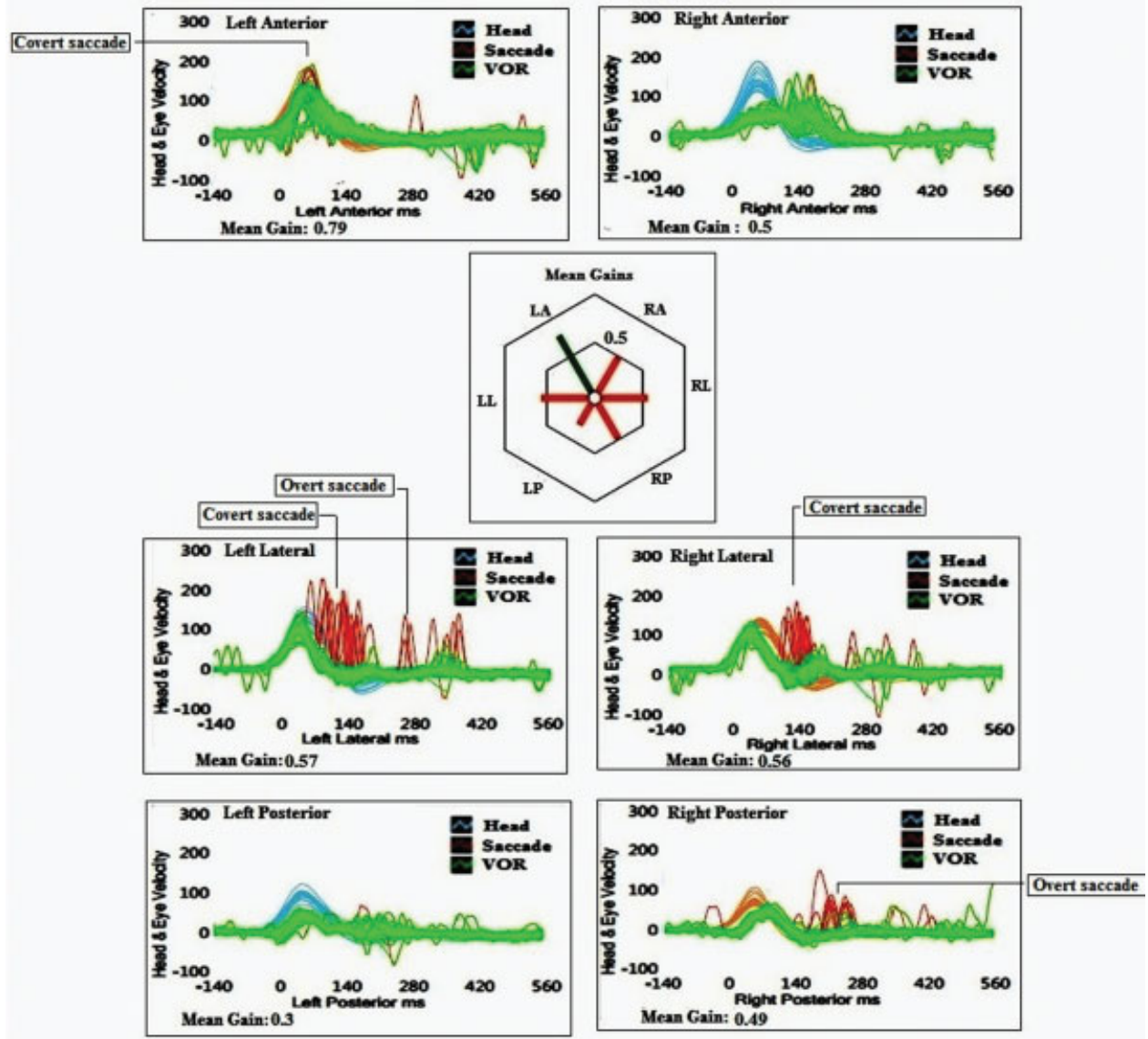

Fig. 2 Video head impulse test results obtained from one of the participant with auditory neuropathy spectrum disorder.

of the individuals with Meniere disease. Taylor et $\mathrm{al}^{32}$ mentioned 43 patients with bilateral vestibular neuritis, out of which $97.7 \%$ had reduced VOR gain values in horizontal canals, $39.5 \%$ in posterior canals, and $90.7 \%$ in anterior canals. The VOR gain has also been reported to be reduced in cases with vestibular schwannoma. ${ }^{33-36}$ The reduction in VOR gain in vestibular schwannoma has been linked to the nerve compression that does not allow the action potentials to travel through the peripheral vestibular system to the vestibular nucleus.

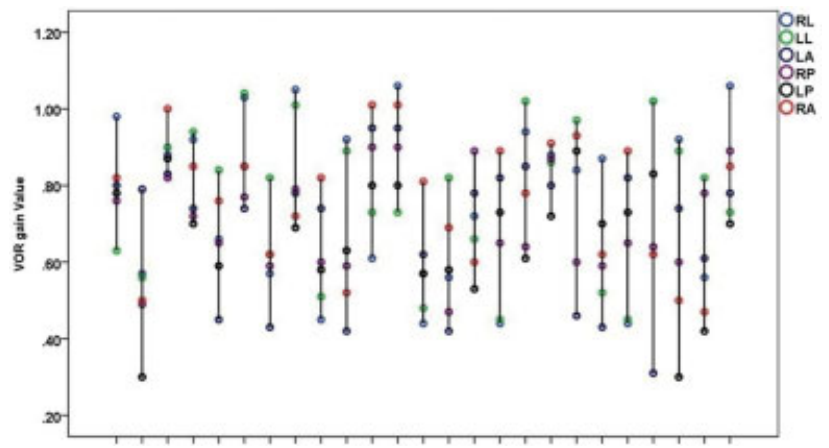

Fig. 3 Vestibulo-ocular reflex gain values of individuals with auditory neuropathy spectrum disorder. Abbreviations: LA, left anterior; LL, left lateral; LP, left posterior; RA, right anterior; RL, right lateral; RP, right posterior; VOR, vestibulo-ocular reflex.
As it has been suggested that individuals with ANSD might have vestibular neuropathy, this neuropathic condition might be interfering with the normal conduction of action potentials between peripheral vestibular receptors and the vestibular nucleus. Neuropathic involvement of the vestibular nerve has been reported by various authors. ${ }^{2,12,14,18}$ Starr et $\mathrm{al}^{37}$ have also reported a beaded appearance of the nerve, along with fragmentation of the myelin sheath. Moreover, a reduced number of nerve fibers between the peripheral vestibular receptors and the vestibular ganglion has also

Table 2 Mean and Standard Deviation of the Vestibulo-ocular Reflex Gain Values for Both Groups

\begin{tabular}{|l|l|l|l|l|}
\hline \multirow{2}{*}{ Semicircular canal } & \multicolumn{2}{|l|}{$\begin{array}{l}\text { Individuals with } \\
\text { ANSD }\end{array}$} & \multicolumn{2}{l|}{$\begin{array}{l}\text { Normal Hearing } \\
\text { Individuals }\end{array}$} \\
\cline { 2 - 5 } & Mean & SD & Mean & SD \\
\hline Left Lateral (LL) & 0.77 & 0.22 & 0.95 & 0.09 \\
\hline Right Lateral (RL) & 0.77 & 0.19 & 1.00 & 0.07 \\
\hline Left Anterior (LA) & 0.68 & 0.18 & 0.90 & 0.10 \\
\hline Right Posterior (RP) & 0.69 & 0.13 & 0.90 & 0.13 \\
\hline Left Posterior (LP) & 0.66 & 0.15 & 0.87 & 0.09 \\
\hline Right Anterior (RA) & 0.76 & 0.16 & 0.98 & 0.15 \\
\hline
\end{tabular}

Abbreviation: SD, standard deviation. 
Table 3 Refixation Saccades at all Six Semicircular Canals Present in the Individuals with Auditory Neuropathy Spectrum Disorder

\begin{tabular}{|l|l|l|l|l|}
\hline $\begin{array}{l}\text { Semicircular } \\
\text { canals }\end{array}$ & $\begin{array}{l}\text { Covert } \\
\text { Saccade }\end{array}$ & $\begin{array}{l}\text { Overt } \\
\text { Saccade }\end{array}$ & $\begin{array}{l}\text { Covert }+ \\
\text { Overt }\end{array}$ & None \\
\hline Left Lateral (LL) & 6 & 5 & 9 & 5 \\
\hline Right Lateral (RL) & 6 & 3 & 11 & 5 \\
\hline Left Anterior (LA) & 4 & 0 & 5 & 16 \\
\hline Right Anterior (RA) & 8 & 0 & 0 & 17 \\
\hline Left Posterior (LP) & 4 & 2 & 3 & 16 \\
\hline $\begin{array}{l}\text { Right Posterior } \\
\text { (RP) }\end{array}$ & 6 & 1 & 4 & 14 \\
\hline
\end{tabular}

Table 4 Correlation Between Duration of Disorder and Vestibulo-ocular Reflex Gain of the Six Semicircular Canals in Individuals with Auditory Neuropathy Spectrum Disorder

\begin{tabular}{|l|l|}
\hline Semicircular Canals & ' $r$ ' Values \\
\hline Left Lateral (LL) & $-0.15^{*}$ \\
\hline Right Lateral (RL) & $0.16^{*}$ \\
\hline Left Anterior (LA) & $0.10^{*}$ \\
\hline Right Anterior (RA) & $0.08^{*}$ \\
\hline Left Posterior (LP) & $-0.04^{*}$ \\
\hline Right posterior (RP) & $0.01^{*}$ \\
\hline
\end{tabular}

Note: * denotes ' $r$ ' values with no significant correlation.

been reported, indicating an axonal degeneration in individuals with ANSD. Also, the demyelinating condition in ANSD results in the disruption of the production, as well as of the propagation of action potentials by the vestibular nerves. This occurs due to a reduction in membrane resistance due to which the action potential does not spread very far before requiring regeneration. ${ }^{35}$ This translates into the inability of the neural pathway, that is, the superior and inferior vestibular nerves, to generate an appropriate amount of action potentials necessary for the VOR reflex pathway to work properly and, hence, the VOR gain is reduced.

Table 5 Correlation Between Vestibulo-ocular Reflex Gain and Pure Tone Thresholds in Individuals with Auditory Neuropathy Spectrum Disorder

\begin{tabular}{|l|l|}
\hline Semicircular Canals & R Values \\
\hline Left Lateral (LL) & 0.14 \\
\hline Right Lateral (RL) & -0.25 \\
\hline Left Anterior (LA) & 0.30 \\
\hline Right Anterior (RA) & 0.04 \\
\hline Left Posterior (LP) & $0.42^{*}$ \\
\hline Right posterior (RP) & 0.01 \\
\hline
\end{tabular}

Note: * denotes significant positive correlation at 0.05 level.
Moreover, one of the participants with ANSD in the current study had normal VOR gain. Various authors have reported that the vestibular tests are not affected in all of the participants with ANSD. For example, Starr et $\mathrm{al}^{3}$ reported caloric responses to be absent in 2 out of 10 individuals with ANSD, Konrádsson ${ }^{38}$ reported normal caloric responses in all of the 4 children diagnosed with ANSD, Fujikawa et al ${ }^{39}$ reported vestibular abnormality in 9 out of 14 participants with ANSD, whereas Kumar et $\mathrm{al}^{12}$ reported vestibular abnormality in $80 \%$ of the participants with ANSD. The reports from various studies indicate that there is a large variability in vestibular test findings in individuals with ANSD. The normal VOR gain in this particular participant could be because of the slow progression of the disease or an early stage of involvement of the vestibular nerves.

In the present study, it was also found that normalhearing individuals had no compensatory saccades, which were found to be present in all of the individuals with ANSD in one or the other canal. Similar reports have been published earlier in various vestibular pathologies. ${ }^{29,40,41}$ Blodow et $\mathrm{al}^{31}$ suggested that compensatory refixation saccades occur as a result of reduced VOR gain in individuals with vestibulopathy. Also, the similar results obtained by Neupane et $\mathrm{al}^{42}$ in individuals with motion sickness recommended compensatory refixation saccades as a good parameter in evaluating these individuals.

Compensatory refixation saccades are indicative of weakened semicircular canals such that it is incapable to stabilize the gaze with the movement of eyes in equal velocity opposite direction to the head rotation. ${ }^{30}$ These occur due to the variation in stimulation between two canals of the same orthogonal plane giving rise to the generation of compensatory eye movement by VOR to retain the gaze stability even while the head is moving. ${ }^{43}$ These ballistic high-velocity refixation saccades can degrade the image in the retina, therefore suppressing the vision in its onset and period of occurrence. ${ }^{44}$ However, it is also the suppressing feature of saccades that help in the removal of those smeared retinal images created due to the insufficient slow-phase eye velocities that are prevalent in most of the vestibular pathologies. $^{45}$

In the present study, the presence of refixation saccades in individuals with ANSD clearly suggests that these individuals have a vestibular loss that might be resulting in difficulty in stabilizing the gaze on the target. Therefore, these saccades are helpful in maintaining gaze, but not with slow compensatory eye movements. It is the high-velocity eye movement seen in refixation saccades that eradicates smeared retinal image caused due to the presence of insufficient VOR. ${ }^{45}$ Hence, the presence of refixation saccades can be one of the parameters indicating vestibular loss in individuals with ANSD.

Also, in the present study, no correlation was found between the VOR gain and the duration of the disorder in individuals with ANSD. None of the previous studies have stated the correlation of VOR gain with the duration of the disorder in individuals with ANSD. In the auditory domain, Jijo et $\mathrm{al}^{46}$ found no significant correlation between the speech 
Table 6 Details of the Chi-squared Test Showing Association Between Presence or Absence of Saccades and Vestibulo-ocular Reflex Gain

\begin{tabular}{|l|l|l|l|l|l|l|l|l|l|l|l|l|l|}
\hline & & LLS & & RLS & & LAS & & RPS & & RAS & & LPS & \\
\hline & & P & A & P & A & P & A & P & A & P & A & P & A \\
\hline LLG & N & 5 & 9 & & & & & & & & & & \\
\hline & R & 3 & 8 & & & & & & & & & & \\
\hline RLG & N & & & 8 & 2 & & & & & & & & \\
\hline & R & & & 2 & 9 & & & & & & & & \\
\hline LAG & N & & & & & 8 & 13 & & & & & & \\
\hline & R & & & & & 0 & 4 & & & & & & \\
\hline RPG & N & & & & & & & 11 & 10 & & & & \\
\hline & R & & & & & & & 2 & 2 & & & & \\
\hline RAG & N & & & & & & & & & 6 & 16 & & \\
\hline & R & & & & & & & & & 0 & 3 & & \\
\hline LPG & $\mathrm{N}$ & & & & & & & & & & & 5 & 17 \\
\hline & R & & & & & & & & & & & 1 & 2 \\
\hline
\end{tabular}

Abbreviation: LAG, left anterior gain; LAS, left anterior saccade; LLG, left lateral gain; LLS, left lateral saccade; LPG, left posterior gain; LPS, left posterior saccade; RAG, right anterior gain; RAS, right anterior saccade; RLG, right lateral gain; RLS, right lateral saccade; RPG, right posterior gain; RPS, right posterior saccade.

identification scores and pure tone thresholds with the duration of the disorder in individuals with ANSD. Also, it was reported to have the group of individuals with ANSD with similar speech identification scores and puretone thresholds even though the duration of the disorder was not the same and vice versa. ${ }^{46}$ Moreover, Spoendlin ${ }^{14}$ reported the presence of idiosyncratic variability in the range of characteristic features of the disorder in each individual with ANSD, even if they had a similar pathophysiology. Hence, these suggest the heterogeneity in the nature of the disorder, which may vary across each individual with ANSD.

Therefore, considering these individualistic variations in the audiological domain, despite the duration of the disorder in individuals with ANSD, one can assume that the functioning of the vestibular portions in these individuals is similar. Thus, the individualistic variations may be seen in each individual, despite the duration of the disorder, giving rise to no correlation of the VOR gain and asymmetry with the duration of the disorder.

In the present study, the dissociation between the vestibular responses and pure tone thresholds might be due to the fact that these are the physiological acts by two different systems (auditory and vestibular systems) in two different manners. Here, the auditory system is known to be responsive to the acoustic signals, and the peripheral vestibular system is responsive to the head movements and balance. Therefore, the physiological basis of these two systems may go differently giving rise to no correlation between the VOR gain and pure tone thresholds. Furthermore, the present study included the assessment of the semicircular canals using the vHIT. The bithermal caloric test could have been a better measure in the comparative study of the results of the lateral canals in both groups. Also, the documentation of the onset of the disease might help in assessing the variation in the characteristic severity expressed by the individual with ANSD.

\section{Conclusion}

In the present study, the VOR gain was found to be reduced in individuals with ANSD. Also, there was no correlation between the VOR test findings with pure tone thresholds and duration of hearing loss. The reduced VOR gain indicates a deficit in the VOR mechanism in individuals with ANSD. The presence of the refixation saccades in ANSD indicates the presence of a compensatory mechanism of VOR in individuals with ANSD. Presence of high-velocity eye movements seen in refixation saccades in ANSD, which eradicates smeared retinal images caused by the presence of insufficient VOR. It is recommended to use the vHIT test in combination with other vestibular tests to understand the VOR compensatory mechanism in individuals vestibular loss.

Conflicts of Interests

The authors have no conflicts of interests to declare.

\section{References}

1 Sheykholeslami K, Kaga K, Murofushi T, Hughes DW. Vestibular function in auditory neuropathy. Acta Otolaryngol 2000;120(07): 849-854

2 Starr A, McPherson D, Patterson J, et al. Absence of both auditory evoked potentials and auditory percepts dependent on timing cues. Brain 1991;114(Pt 3):1157-1180

3 Starr A, Picton TW, Sininger Y, Hood LJ, Berlin CI. Auditory neuropathy. Brain 1996;119(Pt 3):741-753 
4 Zeng FG, Liu S. Speech perception in individuals with auditory neuropathy. J Speech Lang Hear Res 2006;49(02):367-380

5 Davis H, Hirsh SK. A slow brain stem response for low-frequency audiometry. Audiology 1979;18(06):445-461

6 Berlin CI. Auditory neuropathy: using OAEs and ABRs from screening to management. Paper presented at the Seminars in Hearing 1999

7 Kumar UA, Jayaram MM. Prevalence and audiological characteristics in individuals with auditory neuropathy/auditory dys-synchrony. Int J Audiol 2006;45(06):360-366

8 Bhat JS, Kumar K, Sinha SK. Auditory Neuropathy/Dys-synchrony In School-aged Hearing-impaired Children: A South Indian Perspective. Asia Pac J Speech Lang Hear 2007;10(03):157-164

9 Samaha M, Katsarkas A. Vestibular impairment in peripheral sensory neuropathies. J Otolaryngol 2000;29(05):299-301

10 Prabhu P, Jamuar P. Prevalence of vestibular symptoms in individuals with auditory neuropathy spectrum disorder - A retrospective study. Intractable Rare Dis Res 2017;6(01):46-49

11 Akdogan O, Selcuk A, Ozcan I, Dere H. Vestibular nerve functions in children with auditory neuropathy. Int J Pediatr Otorhinolaryngol 2008;72(03):415-419

12 Kumar K, Sinha SK, Singh NK, Bharti AK, Barman A. Vestibular evoked myogenic potential as a tool to identify vestibular involvement in auditory neuropathy. Asia Pac J Speech Lang Hear 2007; 10(03):181-187

13 Sinha SK, Barman A, Singh NK, Rajeshwari G, Sharanya R. Vestibular test findings in individuals with auditory neuropathy: review. J Laryngol Otol 2013;127(05):448-451

14 Spoendlin H. Optic cochleovestibular degenerations in hereditary ataxias. II. Temporal bone pathology in two cases of Friedreich's ataxia with vestibulo-cochlear disorders. Brain 1974;97(01): 41-48

15 Ismail NM, Makky SA, Besher AE, Galhom DH. Evaluation of cochlea-vestibular functions in patient with auditory neuropathy. Eygptian J Ear Nose Throat Allied Sci 2014;15:117-124

16 Abdel-Nasser AA, Elkhayat NM, Khalil SH, Mahmoud LH. Audiovestibular and neurological correlates in patients with auditory and peripheral neuropathy. Egypt J Neurol Psychiat Neurosurg 2006;43:253-267

17 Sinha SK, Bansal S. Assessment of Semicircular Canal Function using vHIT in Adults with Congenital Hearing Loss. Annals Otolaryngol Rhinol 2017;4:1188

18 Perez N, Rama-Lopez J. Head-impulse and caloric tests in patients with dizziness. Otol Neurotol 2003;24(06):913-917

19 Halmagyi GM, Curthoys IS. A clinical sign of canal paresis. Arch Neurol 1988;45(07):737-739

20 MacDougall HG, Weber KP, McGarvie LA, Halmagyi GM, Curthoys IS. The video head impulse test: diagnostic accuracy in peripheral vestibulopathy. Neurology 2009;73(14):1134-1141

21 McCaslin DL, Jacobson GP, Bennett ML, Gruenwald JM, Green AP. Predictive properties of the video head impulse test: measures of caloric symmetry and self-report dizziness handicap. Ear Hear 2014;35(05):e185-e191

22 Bansal S, Sinha SK. Assessment of VOR gain function and its testretest reliability in normal hearing individuals. Eur Arch Otorhinolaryngol 2016;273(10):3167-3173

23 Blödow A, Heinze M, Bloching MB, von Brevern M, Radtke A, Lempert T. Caloric stimulation and video-head impulse testing in Ménière's disease and vestibular migraine. Acta Otolaryngol 2014;134(12):1239-1244

24 Bartolomeo M, Biboulet R, Pierre G, Mondain M, Uziel A, Venail F. Value of the video head impulse test in assessing vestibular deficits following vestibular neuritis. Eur Arch Otorhinolaryngol 2014;271(04):681-688

25 Sinha SK, Shankar K, Sharanya R. Cervical and ocular vestibular evoked myogenic potentials test results in individuals with auditory neuropathy spectrum disorders. Audiology Res 2013;3 (01):e4
26 McGarvie LA, MacDougall HG, Halmagyi GM, Burgess AM, Weber KP, Curthoys IS. The Video Head Impulse Test (vHIT) of Semicircular Canal Function - Age-Dependent Normative Values of VOR Gain in Healthy Subjects. Front Neurol 2015;6:154

27 Carhart R, Jerger JF. Preferred method for determination of puretone thresholds. J Sph Hear Dis 1959;24:330-345

28 Patterson JN, Bassett AM, Mollak CM, Honaker JA. Effects of hand placement technique on the video head impulse test (vHIT) in younger and older adults. Otol Neurotol 2015;36(06):1061-1068

29 Macdougall HG, McGarvie LA, Halmagyi GM, Curthoys IS, Weber KP. The video Head Impulse Test (vHIT) detects vertical semicircular canal dysfunction. PLoS One 2013;8(04):e61488

30 MacDougall HG, McGarvie LA, Halmagyi GM, et al. A new saccadic indicator of peripheral vestibular function based on the video head impulse test. Neurology 2016;87(04):410-418

31 Blödow A, Pannasch S, Walther LE. Detection of isolated covert saccades with the video head impulse test in peripheral vestibular disorders. Auris Nasus Larynx 2013;40(04):348-351

32 Taylor RL, McGarvie LA, Reid N, Young AS, Halmagyi GM, Welgampola MS. Vestibular neuritis affects both superior and inferior vestibular nerves. Neurology 2016;87(16):1704-1712

33 Tranter-Entwistle I, Dawes P, Darlington CL, Smith PF, Cutfield N. Video head impulse in comparison to caloric testing in unilateral vestibular schwannoma. Acta Otolaryngol 2016;136(11): $1110-1114$

34 Batuecas-Caletrio A, Klumpp M, Santacruz-Ruiz S, Benito Gonzalez F, Gonzalez Sánchez E, Arriaga M. Vestibular function in cochlear implantation: Correlating objectiveness and subjectiveness. Laryngoscope 2015;125(10):2371-2375

35 Eza-Nuñez P, Fariñas-Alvarez C, Perez-Fernandez N. The caloric test and the video head-impulse test in patients with vertigo. J Int Adv Otol 2014;10:144-149

36 Weber KP, Aw ST, Todd MJ, McGarvie LA, Curthoys IS, Halmagyi GM. Head impulse test in unilateral vestibular loss: vestibuloocular reflex and catch-up saccades. Neurology 2008;70(06): 454-463

37 Starr A, Michalewski HJ, Zeng FG, et al. Pathology and physiology of auditory neuropathy with a novel mutation in the MPZ gene (Tyr145->Ser). Brain 2003;126(Pt 7):1604-1619

38 Konrádsson KS. Bilaterally preserved otoacoustic emissions in four children with profound idiopathic unilateral sensorineural hearing loss. Audiology 1996;35(04):217-227

39 Fujikawa S, Starr A. Vestibular neuropathy accompanying auditory and peripheral neuropathies. Arch Otolaryngol Head Neck Surg 2000;126(12):1453-1456

40 Guerra Jiménez G, Pérez Fernández N. Reduction in posterior semicircular canal gain by age in video head impulse testing. Observational study. Acta Otorrinolaringol Esp 2016;67(01): $15-22$

41 Redondo-Martínez J, Bécares-Martínez C, Orts-Alborch M, GarcíaCallejo FJ, Pérez-Carbonell T, Marco-Algarra J. Relationship between video head impulse test (vHIT) and caloric test in patients with vestibular neuritis. Acta Otorrinolaringol Esp 2016;67(03): 156-161

42 Neupane AK, Gururaj K, Sinha SK. Higher Asymmetry Ratio and Refixation Saccades in Individuals with Motion Sickness. J Am Acad Audiol 2018;29(02):175-186. Doi: 10.3766/jaaa.16175

43 Bronstein AM, Gresty MA. Compensatory eye movements in the presence of conflicting canal and otolith signals. Exp Brain Res 1991;85(03):697-700

44 Matin E. Saccadic suppression: a review and an analysis. Psychol Bull 1974;81(12):899-917

45 Macdougall HG, Curthoys IS. Plasticity during vestibular compensation: the role of saccades. Front Neurol 2012;3:21

46 Jijo P, Yathiraj A. Audiological characteristics and duration of the disorder in individuals with auditory neuropathy spectrum disorder (ANSD) - a retrospective study. J Indian Sp Hear Assoc 2012; 26(01):17-26 